with delight and relief, for it taught for the first time the correct appreciation of disease of the nervous system from the disturbance of function and how the particular situation and nature of the diseased process was to be arrived at from the observation and correlation of the symptoms. Since that time each new edition has recorded the steady progress in our knowledge of this field of medicine and the application of the newer developments in technique as employed in the clinical investigation of a case of disease of the nervous system. In this latter field the present edition deserves special mention for the chapter on the examination of the cerebro-spinal fluid, and the portions dealing with the use of air (encephalography), and of radio-opaque substances introduced into the circulation and the ventricular system in the diagnosis of cerebral disease, and particularly cerebral tumours. Another feature of the book which is worthy of special remark is the profusion of well chosen and beautifully reproduced illustrations.

\section{DIAGNOSIS OF SOME DELUSIONAL INSANITY TYPES IN GENERAL PRACTICE.}

By Edwin Hopewell Ash, M.D., Lond. John Bale, Sons \& Danielsson. 1936. Price 2/6.

This compact monograph is written for the use of the medical practitioner. Emphasis is given to the importance of treating psychotic patients at an early stage of schizophrenia. The writer points out quite rightly that delusional patients are not necessarily hallucinated in the early stages of these malignant reaction-types.

The writer exemplifies the different types of Schizophrenics by summarizing concrete cases which he has personally observed in his practice.

\title{
Miscellaneous.
}

This Section deals with New Drugs, Preparations, Surgical Instruments, etc. The description of each article is supplied by the Producer. Particulars regarding insertions, which are free of cost, may be obtained from the Business Manager, Fellowship of Medicine and Post-Graduate Journal, 519, Grand Buildings, W.C.2.

The Armour Laboratories announce the introduction of two additional preparations to the "Glanoid" range of Armour and Medicinal Products of Co. Ltd. Animal Origin.

Concentrate Capsules.

$$
\text { 1. "Glanoid" Suprarenal }
$$

$$
\text { 2. "Glanoid" "Salfel " (Enteric }
$$

Coated Bile Salts) Tablets.

"GLANOID" SUPRARENAL CONCENTRATE CAPSULES contain that fraction, extracted from Suprarenal tissue, which possesses therapeutic properties in the treatment of certain allegeric manifestations and also in treating œedema of unknown ætiology.

Clinical experience has revealed that the concentrate has remarkable power to ameliorate symptoms associated with these allergic conditions. The concentrate aids in the control of the water and sodium chloride balance of the extra-cellular body fluids and some evidence is being accumulated which indicates an effect also on the sugar tolerance of allergic individuals.
" Glanoid " Suprarenal Concentrate Capsules will be found to be of value in combating œedema of allergic origin, Hay Fever, Urticaria, Asthma and Migraine.

The dose varies but as a rule one or two Grain 2 capsules after meals is sufficient.

Supplied in Grain 2 capsules. Bottles of 25 - 7s., 50 - 12s. 6d., 100 - 21s.

" GLANOID " “SALFEL" TABLETS contain Sodium Glycocholate and Sodium Taurocholate in the proportion existing in fresh bile. Owing to the bitter taste and specific action of Bile Salts in the intestine, the tablets are supplied in 1 and 3 Grain Enteric Coated tablets.

Bile Salts medication is indicated in a variety of conditions in which there is a diminution in the amount of bile in the intestinal tract. Bile Salts assist both pancreatic digestion and normal peristalsis and provide a powerful stimulant to the secretory activity of the liver.

"Salfel" is supplied in bottles of 100 tablets 1 Grain $5 \mathrm{~s}$. 6d. and 3 Grains 8s. 6d. 